\title{
Tyrosine pathway regulation is host-mediated in the pea aphid symbiosis during late embryonic and early larval development
}

\author{
Andréane Rabatel ${ }^{1,3}$, Gérard Febvay ${ }^{2,3}$, Karen Gaget ${ }^{2,3}$, Gabrielle Duport ${ }^{2,3}$, Patrice Baa-Puyoulet ${ }^{2,3}$, \\ Panagiotis Sapountzis ${ }^{2,3}$, Nadia Bendridi 1,3, Marjolaine Rey ${ }^{2,3}$, Yvan Rahbé ${ }^{2,3,4}$, Hubert Charles 1,3,4, \\ Federica Calevro ${ }^{1,3^{*}}$ and Stefano Colella $a^{2,3^{*}}$
}

\begin{abstract}
Background: Nutritional symbioses play a central role in insects' adaptation to specialized diets and in their evolutionary success. The obligatory symbiosis between the pea aphid, Acyrthosiphon pisum, and the bacterium, Buchnera aphidicola, is no exception as it enables this important agricultural pest insect to develop on a diet exclusively based on plant phloem sap. The symbiotic bacteria provide the host with essential amino acids lacking in its diet but necessary for the rapid embryonic growth seen in the parthenogenetic viviparous reproduction of aphids. The aphid furnishes, in exchange, non-essential amino acids and other important metabolites.

Understanding the regulations acting on this integrated metabolic system during the development of this insect is essential in elucidating aphid biology.
\end{abstract}

Results: We used a microarray-based approach to analyse gene expression in the late embryonic and the early larval stages of the pea aphid, characterizing, for the first time, the transcriptional profiles in these developmental phases. Our analyses allowed us to identify key genes in the phenylalanine, tyrosine and dopamine pathways and we identified ACYPI004243, one of the four genes encoding for the aspartate transaminase (E.C. 2.6.1.1), as specifically regulated during development. Indeed, the tyrosine biosynthetic pathway is crucial for the symbiotic metabolism as it is shared between the two partners, all the precursors being produced by B. aphidicola. Our microarray data are supported by HPLC amino acid analyses demonstrating an accumulation of tyrosine at the same developmental stages, with an up-regulation of the tyrosine biosynthetic genes. Tyrosine is also essential for the synthesis of cuticular proteins and it is an important precursor for cuticle maturation: together with the up-regulation of tyrosine biosynthesis, we observed an up-regulation of cuticular genes expression. We were also able to identify some amino acid transporter genes which are essential for the switch over to the late embryonic stages in pea aphid development.

Conclusions: Our data show that, in the development of A. pisum, a specific host gene set regulates the biosynthetic pathways of amino acids, demonstrating how the regulation of gene expression enables an insect to control the production of metabolites crucial for its own development and symbiotic metabolism.

Keywords: Symbiosis, Pea aphid, Metabolism, Development, Viviparous parthenogenesis, Amino acids, Tyrosine pathway, Cuticle formation, Microarrays transcriptome analysis

\footnotetext{
* Correspondence: federica.calevro@insa-lyon.fr; stefano.colella@lyon.inra.fr

${ }^{1}$ Insa-Lyon, UMR203 BF2I, Biologie Fonctionnelle Insectes et Interactions,

Villeurbanne F-69621, France

${ }^{2}$ Inra, UMR203 BF2I, Biologie Fonctionnelle Insectes et Interactions,

Villeurbanne F-69621, France

Full list of author information is available at the end of the article
} 


\section{Background}

Symbiosis plays a key role in the life of many insects that live on nutritionally unbalanced diets, such as plant sap, blood or grain [1,2]. The adaptation of these insects to such food sources is possible only in association with certain microorganisms that are specialized in nutritional complementation. Endosymbiosis is, thus, a central process in these animals and more than $10 \%$ of insect species depend on intracellular bacteria for their development and survival [3]. This is true for aphids that feed on phloem sap [4], a very unbalanced diet that is characterized by a high concentration of sucrose and by very low levels of several essential amino acids crucial to the development of these metazoans [5]. The obligate intracellular symbiotic bacteria in aphids belong to the Buchnera genus and they provide these important pest insects with the essential amino acids lacking in their diet [6-10]. Symbiotic bacteria are contained in specialized host cells, called bacteriocytes, that are localised in the abdominal haemocoel, close to the ovaries in sexual and asexual females [1]. In fact, aphids have a life cycle that alternates sexual and asexual reproduction [11] and the success of aphids as crop pests is enhanced by their phenomenal reproductive rates, through viviparous parthenogenesis, during spring and summer. Parthenogenetic viviparous females have two ovaries, each containing several ovarioles. In the pea aphid, Acyrthosiphon pisum, embryos at different stages of development can be observed, at any given time, within six or seven ovarioles $[12,13]$ and an adult asexual female reared in the laboratory produces an average of 130 embryos during her lifespan. The vertical transmission process of the symbionts is vital for the reproductive success of aphids and it takes place at the end of blastoderm formation in the A. pisum embryonic development [13,14]. At this stage, approximately 1000 Buchnera aphidicola bacteria are transmitted from maternal bacteriocytes to a single viviparous embryo, and they increase in number by 120 fold during the remaining embryonic development [1,13,15-17].

The importance of $B$. aphidicola nutritional complementation was initially indicated by the observation that aposymbiotic aphids (in which the symbiotic bacteria have been depleted using an antibiotic treatment) show significantly reduced growth and reproductive rates [18-22]. A. pisum has been extensively used in laboratory studies and its genome has been recently sequenced and annotated [23]. Several B. aphidicola genomes, from different aphid species [10,24-27] and from strains of pea aphid [28], have also been sequenced. In fact, a comparison between the pea aphid genome and that of its symbiont $[10,28]$ confirmed the previously hypothesized integrated metabolism for these two organisms, in particular for the amino acid pathways $[23,29,30]$. The symbiotic bacterial genome includes genes for almost all enzymes involved in the essential amino acid pathways, while the few missing genes in the leucine, isoleucine, valine, methionine and phenylalanine pathways are present in the host genome [10,29]. A recent RNAseq transcriptome study of maternal bacteriocytes, compared with other tissues, supports the integrated nature of the host-symbiont metabolic network: this is demonstrated by specific gene expression regulations of amino acid metabolism genes in the symbiotic compartment, compared with other aphid body compartments [31].

The availability of the genome sequences for both partners of this symbiosis opens up several new research perspectives for this genomic model of symbiosis $[32,33]$. Functional genomics will help to characterize the role of different genes, and their regulation, in different physiological processes that contribute to the reproductive and ecological success of aphids. As seen in several other symbiotic bacteria, the $B$. aphidicola genome is reduced in size when compared to that of free-living bacteria [34] and it shows a clear reduction in the classic bacterial gene expression regulatory networks (reviewed in [35]). Several studies have indicated the lack of a strong and specific transcriptional response of this bacterium following a stress applied to the aphid host [36-38]. Nevertheless, a structured link between the organization of genes on the chromosome and gene transcription levels is conserved in B. aphidicola, as compared to the phylogenetically related free-living bacteria [39], and, more recently, a specific transcriptional response of the pLeu plasmid to a leucine stress applied to the pea aphid host has been demonstrated [40]. The integrated metabolism of the two partners indicates that the $B$. aphidicola regulatory capability is connected to the host transcriptional responses to stress events or to different physiological conditions. Certain studies have analysed the pea aphid transcriptome in different tissues and physiological conditions [38,41-47], but no global gene expression analysis of the aphids' parthenogenetic embryonic development has yet been performed.

Although the metabolic complementation between $B$. aphidicola and aphids is important throughout their life cycle, the symbiosis is thought to play a key role during the parthenogenetic embryo development (reviewed in [48]). For example, embryonic growth in aphids is highly dependent on bacterial-derived phenylalanine and tryptophan and, to a lesser extent, on methionine and lysine [49]. After microinjections of radioactively labelled amino acids into the haemocoel of adult aphids, the selective uptake of phenylalanine and lysine by embryos confirms their specific metabolic needs [50]. It is difficult to determine whether this requirement for a high level of amino acids in pea aphid embryos is supported by the maternal tissues (maternal bacteriocytes and/or other tissues) or by the embryonic complement of the symbiotic bacteria localized in the embryonic bacteriocytes. It has been established that late embryos can rely on their own complement of symbiotic bacteria for a supply of essential 
amino acids, particularly for the aromatic amino acids [51]. More recently, a study on the embryos of the black bean aphid Aphis fabae, maintained in vitro with artificial diets lacking amino acids, confirmed the importance of certain amino acid supplies, specifically phenylalanine and valine, acquired exogenously from $B$. aphidicola in the maternal symbiosis, and tryptophan, acquired endogenously from symbiotic bacteria within the embryo [52].

In all the early ex vivo studies of embryonic nutritional needs, the ovaries were always analysed as a whole and, consequently, no data on the distinct embryonic developmental stages were available. More recently, a study on the separate stages was performed to assess $B$. aphidicola transcriptional changes during development [53]. This work revealed that the number of $B$. aphidicola genes differentially expressed between embryos and maternal tissues varies significantly among the early, intermediate and late embryos, indicating that the symbiotic interactions between the developing host and its bacterial partner are dynamic, changing in response to the developmental age of the host. The availability of the A. pisum genome prompted us to complement this work with an analysis of pea aphid transcription profiles during parthenogenetic development. Using a NimbleGen custom microarray, we analysed the host transcriptome comparing different developmental groups, thus generating a complete analysis of gene expression during viviparous parthenogenesis of a symbiotic insect. These transcriptomic data were coupled with an analysis of amino acid metabolism, which enabled us to identify some key aspects of the contribution of the symbiotic partners to the metabolic needs of developing parthenogenetic embryos.

\section{Results}

Global analysis of gene expression during embryonic development

Using the newly developed "INRA-BF2I_A.pisum_Nim blegen-ACYPI_4x72k_v1” microarray (ArrayExpress design ID: A-MEXP-1999), built on the pea aphid genome v1.0 assembly [23], we obtained gene expression profiles of aphid embryos belonging to three distinct groups, namely early (EE), intermediate (IE) and late (LE) embryos, collected according to their developmental stage (see Table 1 and Figure 1A), together with aphids at their first larval stage (L1). Three biological replicates were used for each experimental group (see Methods section for further details).

To check the overall quality of the data, after nor malization, we performed an unsupervised cluster analysis using the $50 \%$ of genes showing the highest SD in all the samples (i.e. 12,005 genes) and, with this approach, we were able to classify the data in the original 4 groups analyzed (Figure 1B), with all the biological replicates clustering together. As this analysis confirmed the reliability of our data following the dissection and isolation of the embryos, we then used all the data available to perform the following pair-wise comparisons: (a) EE vs. IE, (b) IE vs. LE and (c) LE vs. L1, using a oneway between groups ANOVA. Among the 24,011 transcripts analyzed, 3,945 (16.4\%) were considered as being significantly differentially expressed during the development of the pea aphid using the following criteria: an adjusted p-value lower than 0.05 and a two-fold change in the considered contrast (see Methods for details of the analysis). Using these criteria, we identified, respectively, $1,264,1,654$ and 2,251 differentially expressed genes for the comparisons EE-IE, IE-LE and LE-L1 (Figure $1 C$ and Additional file 1: Table S1). We observed an increase in the total number of genes differentially expressed during development, whereas the proportion of up-regulated genes decreased by $78.6 \%, 66.0 \%$ and $51.3 \%$, respectively, in the three sequential comparisons EE-IE, IE-LE and LE-L1. This observation shows an activation of the expression of many genes in the earlier stages (comparison EE vs. IE), followed by a down-regulation of the genes important for development and not needed for the first instar larval stage aphids (L1). An analysis of the intersection between stages allowed us to characterize the

Table 1 Description of embryonic and larval stages used for the transcriptomic and amino acid content analyses

\begin{tabular}{|c|c|c|c|c|c|}
\hline & Group & $\begin{array}{c}\text { Group } \\
\text { abbreviation }\end{array}$ & $\begin{array}{l}\text { Developmental } \\
\text { stages }\end{array}$ & $\begin{array}{c}\text { Size } \\
\text { (length or weight) }\end{array}$ & External morphological features \\
\hline \multirow{3}{*}{ Embryos } & Early embryos & $\mathrm{EE}$ & $0-15$ & $\leq 400 \mu \mathrm{m}$ & *No visible eyes *Very slight body pigmentation \\
\hline & Intermediate embryos & $\mathrm{IE}$ & $16-18$ & $400-800 \mu \mathrm{m}$ & $\begin{array}{l}\text { *Developing eye spots in many individuals } \\
\text { *Pigmented bodies }\end{array}$ \\
\hline & Late embryos & LE & $19-20$ & $>800 \mu \mathrm{m}$ & $\begin{array}{l}\text { *Developed eye spots in all individuals } \\
\text { *Highly pigmented bodies }\end{array}$ \\
\hline \multirow{3}{*}{ Larvae } & & L1 & & & $0-24$ hours old \\
\hline & First instar larvae & L1 early & $1^{\text {st }}$ larval & $\leq 0.2 \mathrm{mg}$ & $\leq 6$ hours old \\
\hline & & L1 late & & & $\geq 15$ hours old \\
\hline
\end{tabular}

Assignment of embryos to the three groups ( $E E$, IE or LE) was based on size range and on morphological criteria detailed in this table (see Figure $1 \mathrm{~A}$ for exemplary microphotographs). The developmental stages were defined according to Miura et al. [13]. Larval stages were determined according to the development time after laying. 


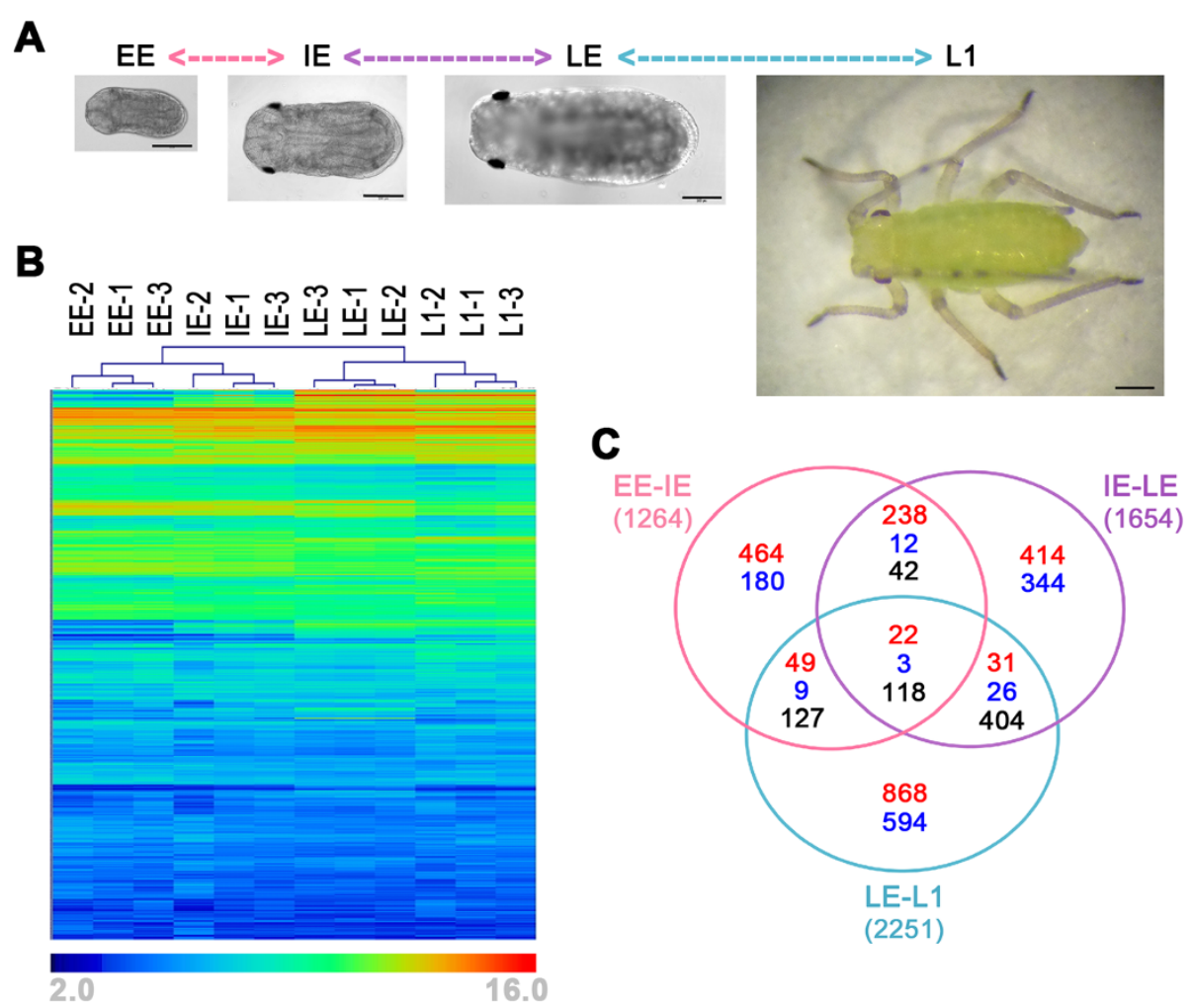

Figure $1 \mathrm{Global}$ expression analysis in pea aphid development. A) Micro-photographs of the four stages analysed in this work where the scale bar represents $200 \mu \mathrm{m}$ in all photographs to allow for size comparison. The microphotographs show just one embryo stage among those belonging to the corresponding groups (see Table 1 for detail). The performed comparisons, early embryos (EE) versus intermediate embryos (IE), intermediate versus late embryos (LE) and late embryos versus first larval stage (L1) are labelled, respectively, in rose, violet and light blue.

B) Unsupervised hierarchical clustering (generated by an average linkage method with euclidean distance and no leaf order optimization) of 50\% of transcripts $(12,005)$ showing the higher standard deviation among all the samples. The colour chart indicates expression intensities using a base 2 logarithmic scale: blue and red represent, respectively, lower (2.0) and upper (16.0) expression intensities (see bottom panel legend). C) The Venn diagram of the 3945 genes showing significantly differential expression in the three comparisons (comparison colour code as in Figure 1A). Numbers in red identify the genes increasing in expression during development; in dark blue, the genes decreasing in expression during development; and, in black, the genes found to be significant in two or more groups where the expression changes are not varying in the same direction in the different comparisons.

developmental switches and to identify significant expression changes. For example, the highest number of common genes is found at the intersection between the IE-LE and LE-L1 comparisons, with 604 genes (Additional file 1: Table S1D). It is worth noting that, out of these 604 genes common to the IE-LE and LE-L1 comparisons, 516 showed expression changes in opposite directions in the two comparisons and, among those, 366 were upregulated between IE and LE and down-regulated between LE and L1. These observations support the fact that numerous genes that are important in development are activated in the early stages and they are gradually repressed in the more advanced stages, up to the L1 stage. On the other hand, between the EE-IE and IE-LE comparisons, we observed a continuity of expression in the majority of common genes (340 out of 435 changed in the same direction, with 322 showing an up-regulation during development). Overall, our results show the expected higher number of genes changing their expression at the transition between the embryonic and larval stages.

\section{Microarray data validation by quantitative RT-PCR}

To validate the data obtained from the microarray analysis in our first experiment, we repeated the experiment for the same four stages and quantified the expression of eight $A$. pisum genes, belonging to four functional classes (3 developmental genes, 3 amino acid pathways genes, 1 cuticular gene and 1 transporter gene), using quantitative reverse transcription-PCR (qRT-PCR). The whole experiment was performed again using three new biological replicates for each stage group and for these samples total RNA was not amplified (see Methods for details). We compared the data obtained from qRT-PCR with that obtained in the independent microarray experiments and found very good concordance, with a Pearson's correlation 
coefficient of $0.87(\mathrm{p}<0.0001)$ between these two datasets (Additional file 2: Table S2) [54].

\section{Developmental genes expression analysis}

Among the 387 pea aphid developmental genes annotated by Shigenobu et al. [55], using homology with Drosophila melanogaster, 368 were present in our microarrays and were analysed. In our dataset, 118 genes (32\%) showed significant differential expression in at least one of the three comparisons we performed (Figure 2A). In the comparisons EE-IE, IE-LE and LE-L1 we found, respectively, 30, 67 and 44 significant variant genes (Figure 2B and Additional file 3: Table S3). Twenty-one genes increased their expression during development, while 80 genes showed decreasing levels of expression. Among these 80 genes, 45 were found only in the comparison IE-LE, i.e. the last of the embryonic developmental stages analyzed in this study. We performed a detailed analysis of two gene classes, as defined in the Shigenobu et al annotation paper [55]: the homeobox-containing genes and the signalling-pathway genes, which are involved in the establishment of anatomical patterns and in the regulation of developmental processes in all the metazoans. Among the 95 homeobox-containing genes annotated in the genome of A. pisum, 27 were identified as differentially expressed in at least one of the three comparisons; the same was true for 32 signalling pathway genes, among the 101 annotated, showing significant differential gene expression at different stages of development (Figure 2A and Additional file 3: Table S3D). We also performed a detailed manual analysis for 80 genes belonging to the six main classes of developmental genes classified as being involved in body axis formation, in embryo segmentation, in germline specification, in neurogenesis and in eye development, together with the Hox genes. Of these 80 genes, only 18 showed differential expression in at least one comparison. None of these genes were up-regulated in the EE-IE and IE-LE comparisons and the majority were down-regulated during development, when comparing IE with LE. A few genes showed up-regulation in the LE to L1 transition, including homologs of the D. melanogaster Tslr, Knrl-1, ci, $H h, U b x$ and so genes (Additional file 3: Table S3).

\section{Gene ontology analysis of significant genes}

We performed an unsupervised analysis of the genes showing significant differential expression in the three comparisons (EE-IE, IE-LE and LE-L1), using an enrichment analysis of the functional classes of genes based on the Gene Ontology (GO) annotation. This analysis revealed 246, 274 and 94 enriched functional classes for the comparisons EE-IE, IE-LE and LE-L1, respectively, thus showing a higher number of gene class changes in the two embryonic development comparisons (Additional file 4: Table S4). We observed enrichment in transporter activity genes both in the EE-IE and IE-LE comparisons, with the presence of amino acid transporters being amongst the most significant. In the IE-LE comparison, the morphogenesis and appendage development genes showed significant changes in expression levels. For the IE-LE and LE-L1 comparisons, the analysis revealed three GO classes involved in the cuticle formation process.

\section{Metabolism gene expression: the amino acid pathways}

To explore the general metabolic changes that take place during the parthenogenetic development of the pea aphid, we analyzed the relevant genes (Additional file 1: Table S1) using the annotations available in the AcypiCyc database, which contains the global reconstruction of the metabolic network of the pea aphid [56]. At least one enzyme-coding gene showed significant differential expression for 43, 74 and 90 pathways in the EE-IE, IE-LE and LE-L1 comparisons, respectively (Additional file 5: Table S5). We classified all these pathways, in AcypiCyc, into five broad groups of compounds: lipids, amino acids, sugars, nucleotides, and others. An analysis of the distribution of genes within these classes, compared with the total number of genes in the pea aphid genome, did not reveal any significant changes that would indicate a class of particular interest. For example, $16.8 \%$ of the total number of differentially expressed enzyme-coding genes in our dataset forms part of the amino acid metabolism group and, in the pea aphid genome, the percentage of genes coding for this class is $16.4 \%$. So, the number of detected genes is not significantly different from the number that would be expected by chance. The same is true for the other classes, but we decided to carry out further gene-by-gene analysis for those classes supposed, a priori, to play an important role in symbiosis or in developmental processes.

In particular, we analyzed in more detail the gene expression profiles of the 135 genes involved in the amino acid biosynthesis or degradation pathways [29], which were present in our overall analysis and which represent one of the key functions in the physiology of pea aphid/ B. aphidicola symbiosis. This analysis revealed that the majority of the genes involved in these pathways are strongly expressed (Figure 3A): $78.5 \%$ of these genes are among the $25 \%$ of genes showing the strongest expression. Of the 135 annotated genes, 23 showed significantly differential expression in our comparisons (with 17 genes increasing and four decreasing in expression and two variations of expression in the opposite direction during development). Among the genes involved in amino acid biosynthesis, the significant ones can be classified into four groups: (1) the aspartate biosynthetic family (Asp, Asn, Met, Cys, Thr, Ile, Lys); (2) the phosphoenolpyruvate biosynthetic family (Phe, Tyr, Trp); (3) the glutamate biosynthetic family (Glu, Gln, Pro, Arg); and (4) the 3-phosphoglycerate biosynthetic family (Ser, Cys, Gly) (Additional file 6: Table S6). 


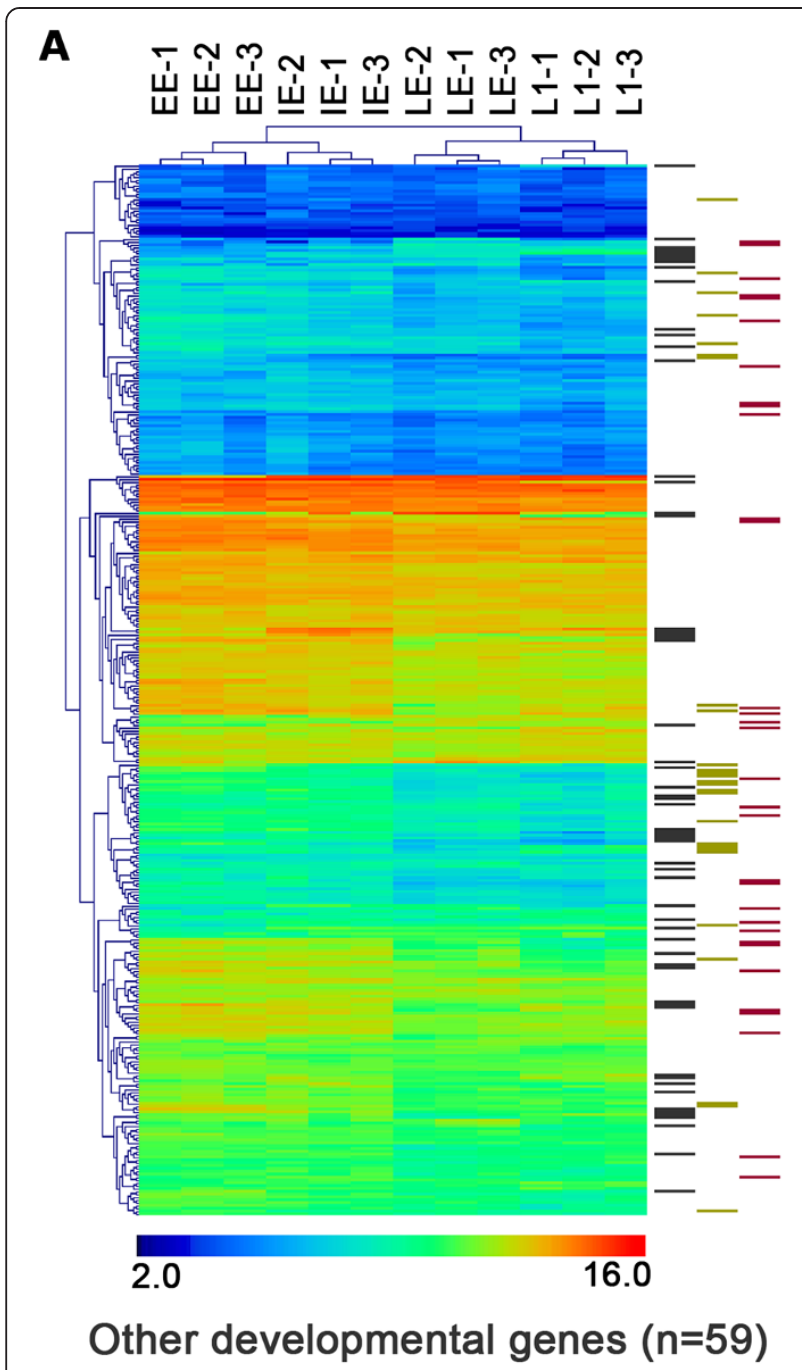

Homeobox-containing genes $(n=27)$ Signalling pathway genes $(n=32)$

B

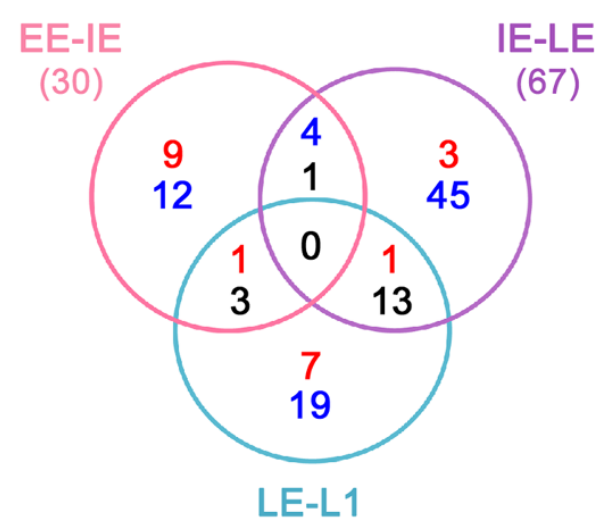

(44)
Figure 2 Developmental gene expression analysis in pea aphid. A) Hierarchical clustering (generated by an average linkage method with euclidean distance and no leaf order optimization) on the 368 developmental genes present on the microarrays (out of the 387 annotated by Shigenobu et al. [55]). The colour chart indicates expression intensities using a base 2 logarithmic scale: blue and red represent, respectively, lower (2.0) and upper (16.0) expression intensities (see bottom panel legend). On the right of the cluster, genes showing significant differential expression in at least one of the comparisons are indicated: in green, 27 homeobox-containing genes; in red, 32 signalling pathways genes; and, in black, 59 other developmental genes. B) The Venn diagram, showing the 118 developmental genes with significantly differential expression in the three comparisons (comparison colour code as in Figure 1A) analysed in this study. Numbers in red identify the genes increasing in expression during development; in dark blue, the genes decreasing in expression during development; and, in black, the genes found to be significant in two or more groups where the expression changes are not varying in the same direction in the different comparisons.

The tyrosine (Tyr) pathway appeared to be particularly interesting with two genes, encoding for the proteins with the enzymatic activities EC 1.14.16.1 and EC 2.6.1.1, showing significantly increased levels of expression during development (Figures 3B and $3 \mathrm{C}$ ). In particular the expression of the ACYPIO07803 gene, which encodes for the enzyme phenylalanine 4-monooxygenase responsible for the synthesis of Tyr in the pea aphid (EC 1.14.16.1), significantly increased in the IE-LE comparison (log2 difference of 3.36 for the IE-LE comparison). Another three genes were annotated as potentially coding for this enzyme: for two of them (ACYPI000847 and ACYPI008168) other EC annotations were supported by the analysis in AcypiCyc (EC 4.2.1.96 and EC 1.14.16.2 respectively), while ACYPIO00175 had a weak annotation score for the enzymatic activity EC 1.14.16.1 but it did not show significant changes in expression.

Four genes in the pea aphid genome (ACYPI000044, ACYPI006213, ACYPI004243, and ACYPI003009) encode for the enzyme aspartate transaminase (EC 2.6.1.1), which catalyzes the synthesis of phenylalanine from phenylpyruvate (Figure 3B). Our gene expression analysis revealed 3 distinct transcription profiles for these four genes (Figure $3 C$ ): ACYPI006213 and ACYPI000044 showed a consistently high level of expression during development, ACYPI003009 gene expression was constant and very low during development, while ACYPI004243 showed a significant change in its expression level. The expression of this gene was relatively low in the early (EE) and intermediate (IE) embryo stages, compared to other genes, but it increased significantly between IE and L1 (2.37 and 2.91 $\log 2$ differences for the IE-LE and LE-L1 comparisons, respectively). The gene expression changes, detected using the microarrays for ACYPIO07803 and ACYPI004243, were also confirmed by specific qRT-PCR experiments (Additional file 2: Table S2). 


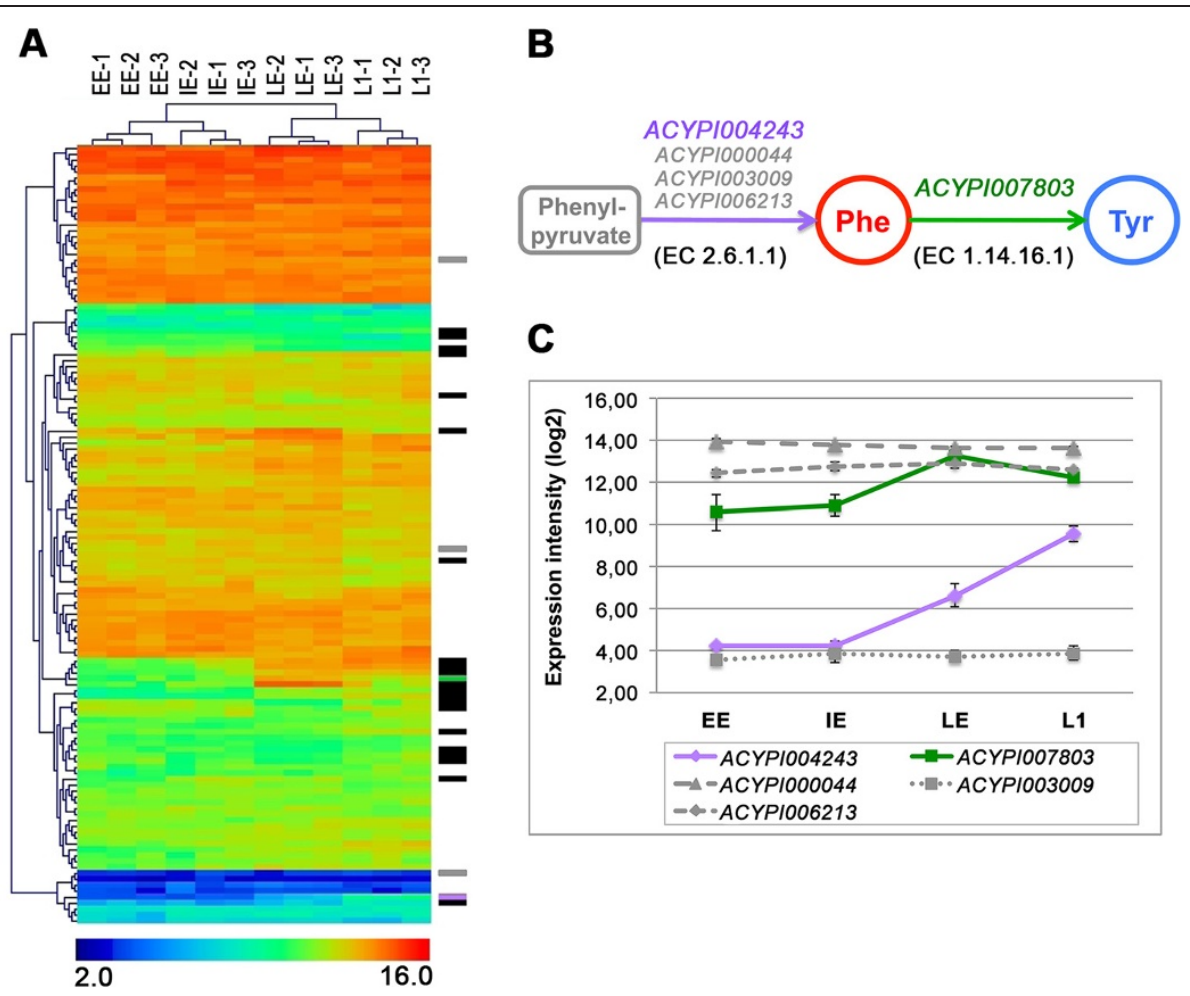

Figure 3 Amino acid metabolism gene expression profiling during pea aphid development. A) Hierarchical clustering (generated by an average linkage method with euclidean distance and no leaf order optimization) of the 135 amino acid metabolism genes annotated by Wilson et al. [29]. The colour chart indicates expression intensities using a base 2 logarithmic scale: blue and red represent, respectively, the lower (2.0) and upper (16.0) expression intensities (see bottom panel legend). On the right of the cluster we reported: in black, the genes varying significantly in at least one of the comparisons, with the exception of the ACYPI007803 gene, shown in green, and ACYPI004243, shown in purple. The three other genes coding the 2.6.1.1 enzyme activity are highlighted in grey but do not vary significantly during development. B) Final steps of the pathway for phenylalanine and tyrosine biosynthesis encoded in the pea aphid genome. C) Expression profiles of the genes involved in the pathway for phenylalanine and tyrosine biosynthesis in the pea aphid. Expression intensity is given as log2. Expression intensities of each stage are means of the three biological replicates.

\section{Amino acid transport activation}

We analyzed, in detail, the amino acid transport function using the recent annotation by Price et al. [57]: our microarray contains probes for 28 of the 40 annotated amino acid transporters and four of the six annotated $\mathrm{Na} / \mathrm{K} / \mathrm{Cl}$ co-transporters of the pea aphid genome. All of the 32 genes represented on the array were detected as expressed in all the samples analyzed. Furthermore, as expected from the GO enrichment analysis, the majority (20 out of 32) of the genes coding for amino acid transporters are part of the significant group in at least one of the three comparisons (Additional file 7: Table S7). Among those genes, six out of 13 members of the eukaryotic specific amino acid/auxin permease (AAAP) family showed significant differential expression during development. With regard to the genes coding for the transporters of the amino acid/polyamine/organocation (APC) family, 11 out of 15 of them showed significant changes in gene expression levels during development. As for the $\mathrm{Na} / \mathrm{K} / \mathrm{Cl}$ co-transporters, needed to create the gradient used by the APC and AAAP transporters, three out of four represented on our microarray showed changes in gene expression. Our data constitute the first characterization of the transcription of amino acid transporter genes during pea aphid development and we found that not all of the genes belonging to the same specific gene family showed differential gene expression. For example, this is the case for the members of the pea aphid slimfast transporter gene family [57] that showed developmental stage-specific expression profiles (Additional file 7: Table S7).

\section{Accumulation of tyrosine in late embryo stages}

We extended the analysis to metabolism by performing free amino acid analysis, using HPLC, on the same embryo groups used in the transcriptome experiments. To analyse the larval stages, on the basis of our transcriptome results, we decided to perform the analysis at two distinct time points of the first larval stage of development in order to monitor, in more detail, any changes in the amino acids content related to cuticle changes in larval growth. Therefore, our HPLC analysis on L1 larvae was performed on two groups: early L1 (age $\leq 6 \mathrm{~h}$, including larvae at the very beginning phases of the cuticle 
maturation after birth) and late L1 (age $\geq 15 \mathrm{~h}$, preparing the cuticle changes for the switch over to the L2 larval stage). The results of this analysis were expressed as a fraction of the total free amino acid content (Additional file 2: Table S8). For histidine and methionine, the concentrations in the EE and IE stages were below the method detection limits. For two amino acids (asparagine and leucine) no significant variation in proportion was observed between any of the stages. The aspartic and glutamic acids (both $\mathrm{p}<0.0001$ ) showed a tendency to decrease their relative concentration during development (Figure 4). Threonine decreased during embryonic development and increased in the larval stages. Four amino acids showed a significant increased relative concentration during development $(p<0.0001)$ : arginine, tyrosine, lysine and proline (Figure 4). Among these amino acids, the greatest difference during development was observed for tyrosine in the late embryo group (LE), showing a six-fold increase in concentration compared with the early embryos (EE). The proportion of free tyrosine decreased rapidly form early to late larvae L1. However, phenylalanine, the precursor of tyrosine, did not show any significant change between any of the stages (Figure 4).

\section{Embryo development specific regulation of the gene ACYPI004243}

The matching profiles of the enzyme-coding gene expression for tyrosine synthesis and the accumulation of this amino acid in the LE and L1 embryo groups prompted us

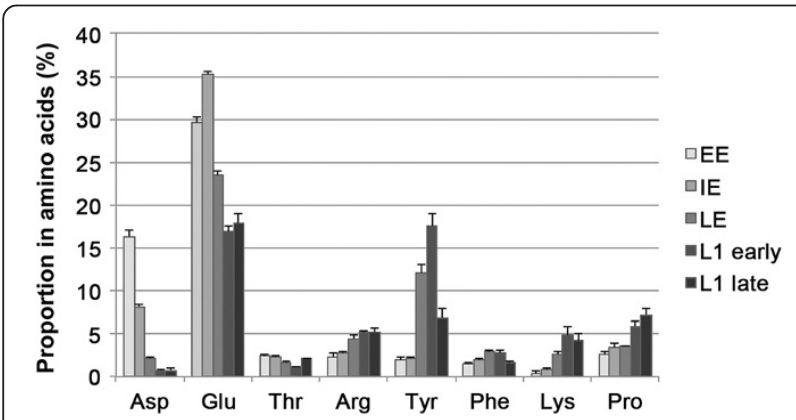

Figure 4 Proportion of free amino acids during pea aphid development. Free amino acid contents of early, intermediate and late embryos, and in the first larval stage taken at two distinct times of development (early $L 1 \leq 6$ hours and late $L 1 \geq 13$ hours). Values $(n=4)$ are expressed as a percentage of the total amount of amino acids in the different samples. Among the 18 amino acids analysed, only those varying the most $(P<0.0001)$ and phenylalanine $(P=0.0015)$, the precursor of tyrosine, are represented. In particular among the significant changes (see Table S8 for details) it is worth noting: a decrease of aspartic acid from $16.3 \%$ in the early embryos (EE) to $0.7 \%$ in L1 larvae; a glutamic acid decrease from IE (35.2\%) to the L1 stages (around 17.4\%); an accumulation of tyrosine during development from $1.9 \%$ in early embryos (EE) to $12.1 \%$ in the late embryo group (LE), accumulation that continues in early first larval stage $(17.6 \%)$ to decrease rapidly to $6.8 \%$ for the late larvae L1. to perform a more detailed analysis of the genes involved in this pathway (Figure 3B and 3C). To gain a better understanding of the differences between the four genes (ACYPI000044, ACYPIO03009, ACYPI004243, and ACYPI 006213), annotated in the AcypiCyc database as coding for the enzyme aspartate transaminase (EC 2.6.1.1), we performed a detailed enzyme gene annotation using the dedicated PRIAM tool [58]. This analysis revealed that, for all of the corresponding proteins, after the primary annotation as enzymatic activity aspartate transaminase (EC 2.6.1.1), two other complementary annotations follow: the enzymatic activity tyrosine transaminase (EC 2.6.1.5) and the enzymatic activity aromatic amino acid transaminase (EC 2.6.1.57) (Additional file 2: Table S9). This additional in silico analysis confirmed the hypothetical role of these four genes in coding the enzymes catalyzing the aspartate, tyrosine and aromatic amino acids transamination reactions. The two more specific annotations of PRIAM are not included in the AcypiCyc database as they did not pass the cut-off point applied in the generation of the database using CycADS [56]. Finally, we analyzed the gene structure and the genome organization of the four genes encoding for the enzyme aspartate transaminase (E.C. 2.6.1.1) in the pea aphid. Among these genes, ACYPI000044 shows a two-exon structure, with the coding sequence restricted to exon 2 , while all the other genes have an 8-exon structure (with the coding sequence spread out between exon 1 and exon 8). It is worth noting that the genes ACYPIO04243 and ACYPI003009 mapped to the same contig in the pea aphid genome. An analysis of the protein sequences was performed and the alignment of the four proteins revealed the expected conservation, with the exception of the ACYPI000044-PA protein sequence that has a unique $\mathrm{N}$-terminal portion which is not aligned to the other three proteins with the enzymatic activity aspartate transaminase (EC 2.6.1.1) (Additional file 8: Figure S1). A detailed phylogenetic analysis of the four aspartate transaminases, expanding the protein information available in PhylomeDB [59] and using the UniProt database [60], was performed (Additional file 9: Figure S2). The evolution of the aspartate transaminases, also called aspartate amino transferases (AAT) family, revealed five major duplications separating bacterial AAT (TyrB and AspC) from mitochondrial AAT (AATM or GOT2) and cytoplasmic eukaryote AAT families (AATC or GOT1). ACYPI000044-PA clearly belongs to mitochondrial AATM. ACYPI006213-PA, ACYPI004243-PA and ACYPI003009-PA diverged more recently and seem to be specific to aphids.

The peculiarity of the ACYPI000044 gene structure, the differences observed in its protein sequence, and its phylogenetic position as regards the mitochondrial AAT prompted us to carry out an additional analysis of the ACYPI000044-PA unique N-terminal sequence. We can 
confirm that this corresponds to the mitochondrial targeting signal peptide. As a result, the ACYPI000044-PA protein has the highest score for potential export to mitochondria, when compared to the other three genes encoding for this enzymatic activity (Additional file 2: Table S10). The gene structure of 23 of the 26 AATM proteins, in the same clade as ACYPI000044-PA, was available (Additional file 9: Figure S2) and it is interesting to note that only two other genes had a single exon encoding the protein: these two genes are from the yeast Schizosaccharomyces pombe and the amoeba Dictyostelium discoideum.

\section{The cuticle formation pathway}

Tyrosine is used to produce DOPA and dopamine, both of which are needed for melanization and sclerotization of the cuticle. Our observation of the increase in cuticle related gene expression between the LE and the L1 stages, coupled with the role of tyrosine as a precursor of cuticle formation processes, prompted us to analyse the DOPA and dopamine synthesis pathway in more detail. In effect, the gene coding for tyrosine 3-monooxygenase (ACYPI 008168), the enzyme catalyzing the reaction converting tyrosine to DOPA (EC 1.14.16.2), showed significant upregulation in the comparison IE vs. LE and a reduction in expression in the passage from LE to L1 (Additional file 10: Table S11A). Multiple pea aphid proteins have been annotated as having the enzymatic activity DOPA decarboxylase (EC 4.1.1.28) in AcypiCyc and, among them, the gene ACYPI009626 received the highest annotation score [56]. It was also seen to be significantly up-regulated in the LE embryo group, compared to IE, and down-regulated in the transition from LE to L1 (Additional file 10: Table S11A). Another six proteins have been annotated as having the enzymatic activity aromatic-L-amino-acid decarboxylase (EC 4.1.1.28) but with a lower score [56]: five of them did not show any change in gene expression during development, while one showed a reduction in expression in the comparison LE vs. L1 (Additional file 10: Table S11A).

We also analyzed the 74 genes annotated as cuticular proteins by the GO annotation and, as expected from our Gene Ontology analysis (GO:0042302), the majority (64 out of 74) showed significant up-regulation during at least one stage in the late developmental phases (IE and LE samples), when the cuticle is being formed. Many of these genes (38 out of 64) showed a significantly lower level of expression in L1, when compared to LE, but others maintained a constant level of expression throughout the subsequent cuticular processes in larval development (Additional file 10: Table S11B).

These data, taken together, demonstrate an up-regulation of the metabolic pathways leading to the synthesis of cuticular proteins and of the key precursors for the process of cuticle melanization and sclerotization, in the LE stage of pea aphid development (Figure 5 and Additional file 10: Table S11).

\section{Discussion}

In this study, the transcriptome analysis of parthenogenetic development in embryonic pea aphids enabled us to characterize the gene expression profiles at key stages in the development of this insect. A comprehensive transcriptome dataset, such as this, is important for the ongoing genome annotation effort as gene expression profiles at specific steps of pea aphid development, or in specific tissues, can lead to an initial characterization of the role of different genes in aphid physiology.

After an unsupervised clustering analysis, that indirectly demonstrated the good quality of our dataset, we identified 3945 genes that showed significant changes in expression level in the developmental groups analysed here (Figure 1). We examined this high number of variant genes, combining unsupervised and hypothesis driven analyses.

We identified the expression profiles of key developmental genes among the ones that had been annotated, in silico, during pea aphid genome analysis [23,55] (Figure 2). Using a global analysis based on gene ontology (GO), we identified biological and cellular processes for which significant expression changes were apparent in the developmental stages under study. Between the IE and LE stages, several significant expression changes in the GO classes are linked, as expected, to the development of appendages and morphogenesis. In both the EE $v s$. IE and IE $v s$. LE comparisons a set of GO classes linked to amino acid transport were identified as changing significantly during development. To further investigate this observation, we analysed the set of pea aphid amino acid transporters recently characterized [57] and we demonstrated a global induction of the majority of these annotated transporter genes during development (Additional file 7: Table S7). These observations represent the first characterization of gene expression profiles of this family of genes involved in amino acid transport during the pea aphid's parthenogenetic development. An intriguing amplification of ortholog genes of the $D$. melanogaster slimfast gene (member of the APC family) has been described in the pea aphid [57] and we have analyzed the gene expression profiles of nine out of the 10 gene copies of this insect genome. Seven of these slimfast orthologs showed increased expression during development in the stages where embryonic growth is greatest (Additional file 7: Table S7B): this observation is in agreement with the role of these genes as nutrient sensors during insect growth [61,62]. Among these slimfast genes showing increasing expression during parthenogenetic development, we find the three paralogs previously identified as having an expression bias in male morphs (ACYPI003240, ACYPI005156 and ACYPI002633) [63]. 


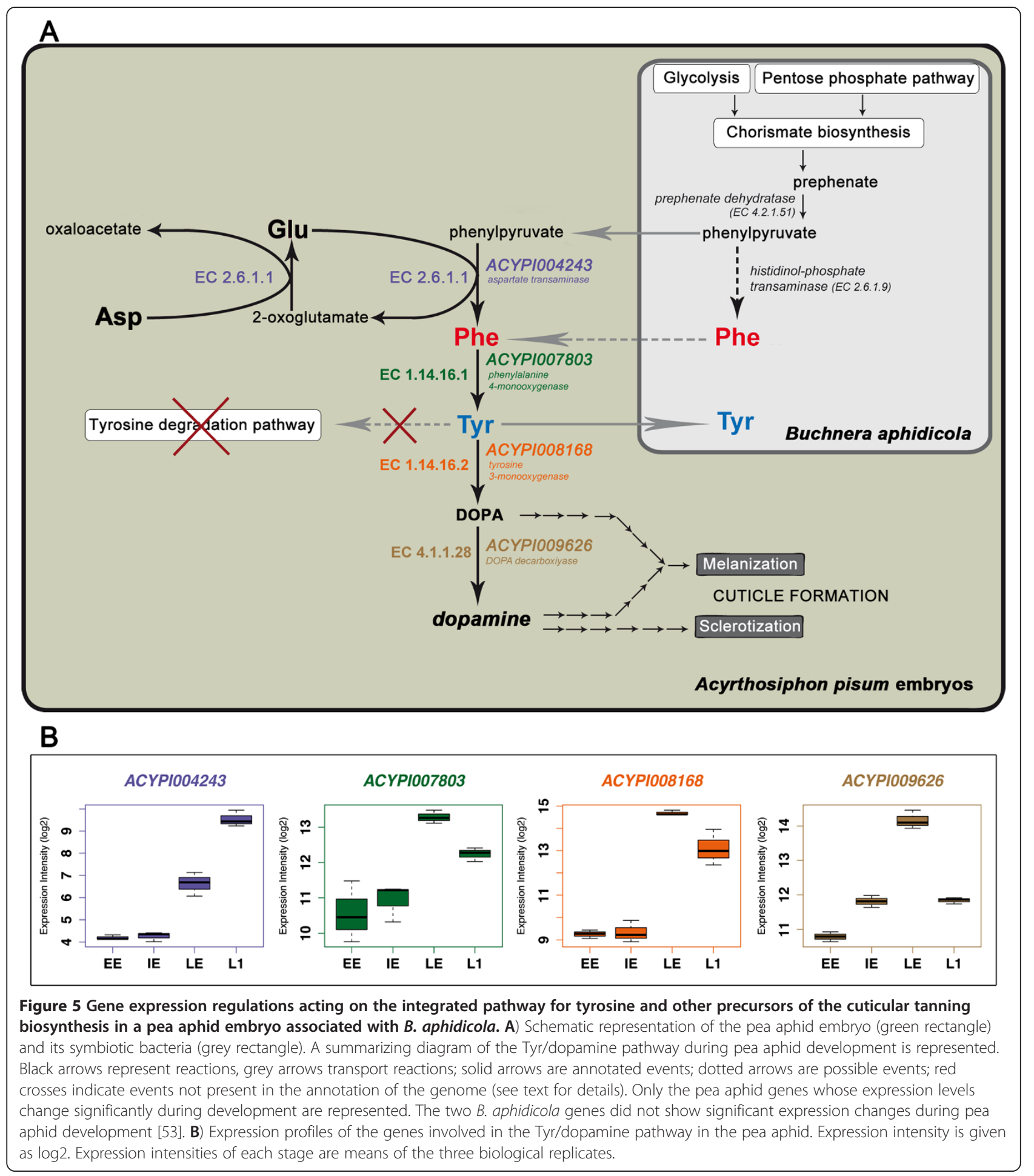

This observation does not contradict the male-biased expression, but further characterization of these genes would be interesting to gain a better understanding of their role in the growth of the different morphs. We can speculate that the expansion of this gene family in the pea aphid genome, and the increased expression of several of these genes during embryonic development, might play a role in the high growth rate observed for parthenogenetic viviparous embryos in this insect. This hypothesis could be confirmed by transcriptional analysis indicating either lower 
gene expression levels or different regulations for the slimfast genes in embryos produced by sexual reproduction and having a low growth rate.

The recent pea aphid genome analysis showed how the enzyme repertoires of the two partners of this metabolically obligatory symbiosis are complementary [23]. A comprehensive analysis of the genes involved in metabolism, performed using the AcypiCyc database annotations [56], did not reveal any significant global change in gene expression in the specific pathways. Nevertheless, the known central role of amino acid metabolism pathways in this symbiotic relationship [29] and, in particular, during pea aphid development [48], together with the induction of expression of the amino acid transporter genes observed in our experiments, prompted us to analyse, in more detail, all the genes involved in the amino acid pathways [29]. Most genes coding for enzymes involved in amino acid metabolism showed strong expression levels (Figure 3), as expected given the central role of amino acids in embryonic development [49-52]. A significant induction of gene expression during pea aphid development, in the stages under study, affects several amino acid pathways (Additional file 6: Table S6). Among these, the pathway for the synthesis of phenylalanine and tyrosine showed significant gene expression changes in both of the enzymatic activities (EC 2.6.1.1 and EC 1.14.16.1) encoded in the pea aphid genome, for the steps complementary to those in $B$. aphidicola (Figure 5). To further investigate this pathway, which plays a key role in this symbiosis, we analysed the content of free amino acids in the same developmental groups studied in the transcriptome analysis. Our HPLC analysis revealed an accumulation of tyrosine in the late embryonic stages (Figure 4), coupled with a decrease in the aspartate content. It is worth noting that this amino acid is located upstream of the tyrosine pathway and is the amino group donor for phenylalanine synthesis (Figure 5). This observed biochemical phenotype corresponds to the induction, during pea aphid development, of the expression of specific genes coding for the enzymes of the final steps of the pathway. Our work demonstrates the existence of an insect specific gene transcription regulation of this key amino acid synthesis and, thus, complements our previous observations of a lack of significant gene expression regulation of the aromatic amino acid pathways in the symbiotic bacteria during embryonic development [53]. The accumulation of tyrosine during pea aphid development is probably facilitated by a total lack of the genes encoding for the tyrosine degradation pathway in this insect genome [23,29], a pathway that is present in 18 other arthropods (only one enzyme missing in Apis mellifera) with a sequenced and annotated genome (http:// arthropodacyc.cycadsys.org/; Baa-Puyoulet et al. manuscript in preparation). Tyrosine has been previously identified as the most abundant free amino acid in body fluids in another aphid species, Uroleucon ambrosiae (Strecker) [64].

A recent RNAseq study on the pea aphid, by Hansen and Moran [31], demonstrated that several genes, coding for key enzymes complementary to the $B$. aphidicola metabolic repertoire, are highly expressed in the bacteriocytes (the aphid symbiotic cells) when compared to the rest of the body, excluding the embryonic compartment. In the present work, we identified two pea aphid genes (ACYPI004243 and ACYPI007803) that are regulated during parthenogenetic and viviparous development to supply the growing embryos with tyrosine, a key precursor to the cuticle formation and sclerotization process. In fact, two other genes, ACYPI008168 and $A C Y$ PI009626, both important for cuticle formation, are up-regulated in the late phases of the pea aphid embryonic development: they code, respectively, for the enzymes catalyzing the reactions that produce DOPA (EC 1.14.16.2) and dopamine (EC 4.1.1.28), starting from tyrosine (Figure 5). DOPA and dopamine participate in the melanization (darkening) and the sclerotization (hardening) of the insects' cuticle formed by cuticular proteins and chitin [65,66]. The observed general increase in cuticular gene expression during the late phases of pea aphid embryo development (Additional file 10: Table S11) demonstrates that all components of this key developmental process in insects are active in the late stages of pea aphid parthenogenetic development.

Among all the transcriptionally regulated genes coding for enzymes that we were able to identify, the most interesting example is aspartate transaminase (E.C. 2.6.1.1). Among the four genes coding for this enzyme, only ACYPI004243 showed significant increases in expression level during pea aphid development while the other three showed a constant expression, albeit at different levels for each gene (Figure 3). However, ACYPI004243 showed a lower expression level in adult bacteriocytes in the RNAseq study, when compared with the entire body (excluding the embryonic compartment) [31]. Among the four genes coding for the enzyme aspartate transaminase (EC 2.6.1.1), ACYPI000044 had the highest level of expression in the adult pea aphid bacteriocytes [31]. In our study, we detected a relatively higher expression of ACYPI000044 in the embryos and larvae, in comparison to the other 3 genes, but the expression levels of this gene did not change during pea aphid development. The same absence of change in expression during development is true for the other two genes, ACYPI006213 and ACYPI003009, which show different levels of expression (Figure $3 \mathrm{C}$ ) that are consistent with the results of RNAseq experiments performed on adult bacteriocytes [31]. Although it is not possible to define the role of each gene coding for the enzymes with aspartate transaminase activity (EC 2.6.1.1) our data demonstrate, for the first time, that among these 
four genes only ACYPIO04243 expression levels increase during the parthenogenetic development of the pea aphid. This observation suggests that, in the pea aphid genome, ACYPIO04243 is controlled by a specific transcriptional regulation mechanism to respond to the need for phenylalanine and tyrosine synthesis during this important phase of development, with a particular link to cuticle formation.

\section{Conclusions}

We have characterized, for the first time, the transcriptional profiles underlying distinct developmental groups in pea aphid parthenogenesis, thus providing new data for gene function annotation and novel hypothesis generation. Furthermore, as a result of the combination of transcriptional profile analysis with a biochemical approach, we were able to show a correlation between gene transcriptional changes at the enzyme level and the accumulation/ decrease of corresponding amino acids, demonstrating an embryo-specific gene regulation in the phenylalanine and tyrosine pathways. The integrated metabolism of the pea aphid and its symbiotic bacteria, B. aphidicola, is far from being completely understood, but our study elucidates, in detail, the role of specific genes in tyrosine metabolism for cuticle formation during the parthenogenetic development of this symbiotic insect.

\section{Methods}

\section{Aphid rearing and embryo isolation}

A long-established parthenogenetic clone (LL01) of $A$. pisum was maintained at $21^{\circ} \mathrm{C}$, with a 16 hour photoperiod, on Vicia faba (L. cv. Aquadulce). In order to have a supply of synchronised aphids and embryos, around one hundred mass-reared winged adults were maintained on young plants and removed after $24 \mathrm{~h}$. The resulting apterous insects were maintained on Vicia faba plants for a nine-day period, until they reached the adult stage.

Embryos were dissected from synchronized parthenogenetic viviparous adult aphids, removing the ovariole sheath in two distinct ice-cold buffers depending on the subsequent analysis. For the total RNA extraction procedure, we used an RNase-free buffer composed of $35 \mathrm{mM}$ Tris- $\mathrm{HCl}$ (pH 7.5), $25 \mathrm{mM} \mathrm{KCl}, 10 \mathrm{mM} \mathrm{MgCl}, 250 \mathrm{mM}$ sucrose, in $0.1 \%$ diethyl pyrocarbonate water. For the HPLC experiments, the buffer contained $162.75 \mathrm{mM} \mathrm{KCl}$, $10 \mathrm{mM} \mathrm{CaCl} 2,25 \mathrm{mM} \mathrm{MgCl} 2,13.75 \mathrm{mM}$ citric acid and $38.75 \mathrm{mM} \mathrm{NaOH}$.

Following a stereoscopical analysis (Olympus IX-81, Olympus, France), embryos were classified according to their length and morphological characteristics into 3 groups: early embryos (EE) $(\leq 0.4 \mathrm{~mm})$, intermediate embryos (IE) (0.4 to $0.8 \mathrm{~mm}$ ) and late embryos (LE) (>0.8 $\mathrm{mm}$ ) corresponding, respectively, to the developmental stages $\leq 15,16-18$ and $19-20$ as described by Miura et al. [13] (Table 1). These groups were chosen because it was easy to distinguish and separate them, during the dissection step, on the basis of well recognizable external morphological criteria. These same developmental stages were also chosen in a previous work on B. aphidicola transcriptome analysis during pea aphid development [53], thus allowing us to make a direct comparison of the transcriptomic data from both the insect host and the symbiotic bacteria.

To obtain synchronized early and late L1, viviparous adults were maintained on young plants for 6 hours. The early L1 (aged from 0 to $6 \mathrm{~h}$ ) were collected and, for the late L1 (aged from 13 to $19 \mathrm{~h}$ ), after having discarded the adults, larvae were maintained for a further $13 \mathrm{~h}$ on the plants prior to collection. For L1 aged from 0 to $24 \mathrm{~h}$, viviparous adults were maintained on young plants for 24 hours and the resulting L1 were collected (Table 1).

\section{RNA extraction}

Total RNA was prepared using the RNeasy mini kit (Qiagen, Hilden, Germany). Three independent extractions were prepared for each group starting from 60 embryos for the EE group, 30 embryos for both the IE and LE groups, and 30 larvae for the L1 group $(0-24 \mathrm{~h})$. It is worth noting that the RNA extractions for the microarray and for the qRT-PCR experiments were performed independently, thus the qRT-PCR data constitute a full biological experimental replicate of the microarray results. For the qRT-PCR, the extraction also included a step of DNase treatment (RNase-Free DNase Set, Qiagen). Total RNA concentration and quality were initially checked using the NanoDrop ${ }^{\circledR}$ ND-1000 spectrophotometer (NanoDrop Technologies, Wilmington, DE, USA) and samples had to meet the following quality parameters: A260/A280 $\geq 1.8$ and $\mathrm{A} 260 / \mathrm{A} 230 \geq 1.8$, in order to be used in the subsequent analysis. The RNA samples were then run using the Agilent RNA 6000 Nano Kit on the Agilent 2100 Bioanalyzer (Agilent Technologies, Palo Alto, CA) to check their integrity. Degraded samples appeared as significantly lower intensity traces, with the main peak area shifted to the lower molecular weights, and they typically exhibited much more noise on the trace. Only good quality samples were used for the subsequent analysis.

\section{Amplification of mRNA and CDNA synthesis}

A limited amount of total RNA was available and we used a T7 RNA polymerase based linear amplification method that has been shown to have no systematic influence on microarray transcription profiles [67]. We used the MessageAmp ${ }^{\mathrm{TM}}$ II aRNA Amplification kit (Ambion, Austin, TX, USA) that preferentially amplifies eukaryotic mRNA. Following the manufacturer's instructions, RNA amplification included five steps: (1) a reverse-transcription using $1 \mu \mathrm{g}$ of total RNA and $1 \mu \mathrm{l}$ of T7-oligo(dT) primers 
(100 ng/ $\mathrm{\mu l}$ ), (2) a second strand cDNA synthesis, (3) a cDNA purification on a DNA filter cartridge, (4) an in vitro transcription and (5) an amplified RNA purification on an aRNA Filter Cartridge. Double strand cDNA was prepared using the Superscript II kit (Invitrogen, Paisley, UK), as recommended by NimbleGen in the NimbleChip ${ }^{\text {TM }}$ Arrays User's Guide for gene expression analysis. Starting with $10 \mu \mathrm{g}$ of aRNA, the samples were processed according to the manufacturer's instructions, including these four steps: (1) an initial cDNA synthesis using random primers, (2) a second strand synthesis, (3) an RNase A clean-up, and (4) a cDNA precipitation. For each sample, the integrity of the aRNA and cDNA was checked using the Agilent RNA 6000 Nano Kit on the Agilent 2100 Bioanalyzer. Only good quality samples were retained for the microarray experiments.

\section{Microarray experiments and data collection}

The "INRA-BF2I_A.pisum_Nimblegen-ACYPI_4x72k_v1" microarray for the pea aphid was developed in collaboration with NimbleGen using the pea aphid genome v1.0 assembly [23]. This NimbleGen $385 \mathrm{~K}$ 4-plex $(4 \times 72,000$ probes) high-density array can accommodate four samples that are hybridized onto a section of the array containing 72,000 60-mers oligonucleotide probes, representing 24,011 pea aphid transcripts (corresponding to 23,855 genes). The microarray design is deposited in the ArrayExpress database (http://www.ebi.ac.uk/arrayexpress/) and the array is available to the International Aphid Genomics Consortium community. On the arrays, 185 probe sets recognise more than one gene: these ACYPI probe sets are labelled with an asterisk $\left(^{*}\right)$ in all of the Results tables and they are listed in full in Table S1E. Labelling (using the NimbleGen OneColor DNA Labelling Kits and Cy3 Random Nonamers), hybridization on the arrays (at $42^{\circ} \mathrm{C}$ for $16-20$ hours) and scanning (using MS 200 Microarray Scanner and the MS 200 Data Collection Software) were carried out by Roche NimbleGen, as described in the NimbleGen arrays user's guide for gene expression arrays, and they provided the final data files. All the transcriptomic data obtained are available in the ArrayExpress database (http://www.ebi.ac. uk/arrayexpress/).

\section{Microarray data analysis}

Microarray data were normalized, using the RMA method [68], and then transformed into $\log 2$. A one-way between groups ANOVA analysis was performed using the Limma package in the $\mathrm{R}$ software [69]: two by two comparisons were performed to identify any differentially expressed genes between the different stages of development (EE-IE; IE-LE; LE-L1). The non-parametric p-values were estimated using 1000 sample permutations and further adjusted using the Benjamini and Hochberg method [70], to limit the number of false positives by a control of the False
Discovery Rate (FDR). For this study we chose an FDR lower than 0.05. A gene was considered significant if its adjusted p-value was lower than 0.05 and if it showed a two-fold change in the considered contrast (see Additional file 1: Table S1 for a detailed list of significantly expressed genes). All HCL (Hierarchical Clustering) analyses were carried out using the TMeV software [71], applying the average linkage method with euclidean distance and no leaf order optimization. Gene Ontology analysis was carried out using the Blast2GO software [72] to perform the GOSSIP test ([73]; http://gossip.gene-groups.net).

\section{Validation of microarray data by qRT-PCR}

Total RNA was reverse-transcribed in cDNA using the SuperScript ${ }^{\mathrm{TM}}$ III First-Strand Synthesis System for RT-PCR (Invitrogen, Paisley, UK), with random primers, according to the manufacturer's instructions. This protocol involved three principal steps: (1) an incubation for $5 \mathrm{~min}$ at $65^{\circ} \mathrm{C}$, (2) a reverse transcription using $1 \mu \mathrm{g}$ of total RNA and including three incubations $\left(25^{\circ} \mathrm{C}, 50^{\circ} \mathrm{C}\right.$ and $\left.85^{\circ} \mathrm{C}\right)$, (3) an RNA matrix degradation using RNase $\mathrm{H}$. Primers to target transcripts (Additional file 2: Table S12) were designed with the Oligo7 software [74], except those used for the genes ACYPI009127 and ACYPI001858 which were taken from Brisson et al. [75]. Real-time PCR was performed in 96-well plates with a LightCycler 480 instrument (Roche diagnostics, Meylan, France). Either $2.5 \mu \mathrm{l}$ of cDNA (at around $1 \mu \mathrm{g} / \mu \mathrm{l}$ ), diluted at $1 / 5$, or water (for negative control reactions) were used in a total PCR reaction final volume of $10 \mu$ l (reagents used from the LightCycler FastStart DNA Master SYBR green I kit by Roche). Amplification conditions were as follows: $95^{\circ} \mathrm{C}$ for $5 \mathrm{~min}$ and then $45 \mathrm{cy}$ cles of $95^{\circ} \mathrm{C}$ for $15 \mathrm{~s}, 53^{\circ} \mathrm{C}$ for $15 \mathrm{~s}$, and $72^{\circ} \mathrm{C}$ for $1 \mathrm{~min}$ $10 \mathrm{~s}$. An internal standard curve was generated for each gene using serial dilutions (from 2000 to $0.0002 \mu \mathrm{g} / \mu \mathrm{l}$ ) of purified PCR products amplified from a pool of cDNA. The PCR reaction, to prepare the control sample for the standard curve, was carried out starting from $1 \mu$ of reverse transcription product using UptiTherm DNA Polymerase (Interchim, Montluçon, France), according to the following protocol: activation of Taq DNA polymerase at $95^{\circ} \mathrm{C}$ for $5 \mathrm{~min}$, followed by 34 three-step amplification cycles consisting of $30 \mathrm{~s}$ denaturation at $95^{\circ} \mathrm{C}, 45 \mathrm{~s}$ annealing at $53^{\circ} \mathrm{C}$, and $45 \mathrm{~s}$ of extension at $72^{\circ} \mathrm{C}$. For the data normalization, two genes were tested in the different developmental stage groups analysed here: actin (ACYPI000064) and rpl32 (ACYPI000074). Real-time RT-PCR data were analysed using the BestKeeper ${ }^{\odot}$ software tool [76] and the actin gene was retained as the best candidate for data normalization. An analysis of the quantitative RT-PCR data was performed using the REST software ([54]; http://rest. gene-quantification.info/). The relative expression ratio of each target gene was calculated by comparing the tested condition against the control condition, and also relative to 
the normalization gene. More precisely, this ratio (R) was calculated taking into account the real-time PCR efficiency of each gene $(\mathrm{E})$ and the crossing point difference $(\triangle \mathrm{CP})$ of a test condition (IE, LE or L1), as compared to the reference condition (EE, IE or LE according to the comparison (EE-IE, IE-LE, LE-L1)), and expressed in comparison to the normalization gene (actin) using the following model [77].

$$
\mathrm{R}=\frac{\left.\left(\mathrm{E}_{\text {target }}\right)^{\Delta \mathrm{CP} \text { target }} \text { (control-sample }\right)}{\left.\left(\mathrm{E}_{\text {reference }}\right)^{\Delta \mathrm{CP} \text { reference }} \text { (control-sample }\right)}
$$

\section{Sample preparation for free amino acid analysis}

For the quantification of free amino acids, we used 20 embryos (Early or Intermediate groups), 15 embryos (Late group) or 15 L1 (0-6 h or 13-19 h) per replicate and the analyses were performed on at least four independent replicates. Samples were crushed in $320 \mu \mathrm{l}$ of ultra-pure water with a known quantity of norvaline used as the internal standard. $200 \mu \mathrm{l}$ of this crude homogenate were used for free amino acid analyses. Free amino acids were extracted from crude homogenate with trichloroacetic acid (TCA, 5\% w/v final concentration), maintained at room temperature for $2 \mathrm{~h}$, vortexed every $30 \mathrm{~min}$, and then centrifuged $\left(10,000 \mathrm{~g}\right.$ for $10 \mathrm{~min}$ at $\left.4{ }^{\circ} \mathrm{C}\right)$. TCA was eliminated from the supernatant by chloroform/ water partition (three successive extractions with $400 \mu \mathrm{l}$ of chloroform), and the final aqueous supernatant was dried under vacuum. All samples were stored at $-20^{\circ} \mathrm{C}$, and then mixed with $80 \mu \mathrm{l}$ of $\mathrm{HCl} 0.1 \mathrm{~N}$ for amino acid analysis.

\section{Amino acid analysis and quantification}

Amino acid analysis was performed by HPLC (Agilent 1100; Agilent Technologies, Massy, France) with a guard cartridge and a reverse phase C18 column (Zorbax EclipseAAA $3.5 \mu \mathrm{m}, 150 \times 4.6 \mathrm{~mm}$, Agilent Technologies), according to the procedure specifically developed for this system [78]. Prior to injection, the sample was buffered with borate at $\mathrm{pH} 10.2$, and primary or secondary amino acids were derivatized with ortho-phthalaldehyde (OPA) or 9-fluorenylmethyl chloroformate (FMOC), respectively. The derivatization process, at room temperature, was automated using the Agilent 1313A autosampler. Separation was carried out at $40^{\circ} \mathrm{C}$, with a flow rate of $2 \mathrm{ml} / \mathrm{min}$, using $40 \mathrm{mM} \mathrm{NaH}_{2} \mathrm{PO}_{4}$ (eluent $\mathrm{A}$, pH 7.8, adjusted with $\mathrm{NaOH}$ ) as the polar phase and an acetonitrile/methanol/water mixture $(45 / 45 / 10, \mathrm{v} / \mathrm{v} / \mathrm{v})$ as the non-polar phase (eluent B). A gradient was applied during chromatography, starting with $20 \%$ of B and increasing to $80 \%$ at the end. Detection was performed by a fluorescence detector set at 340 and $450 \mathrm{~nm}$ of excitation and emission wavelengths, respectively (266/305 $\mathrm{nm}$ for proline). These conditions do not allow for the detection and quantification of cystine and tryptophan, so only 18 amino acids were quantified. For this quantification, norvaline was used as the internal standard and the response factor of each amino acid was determined using a $250 \mathrm{pmol} / \mu \mathrm{l}$ standard mix of amino acids. The software used was the ChemStation for LC 3D Systems (Agilent Technologies).

The comparison of the relative concentrations of free amino acids in the aphid at the various developmental stages (expressed as \% of total free amino acids) was performed, after angular transformation to normalize data, using a one-way ANOVA followed by a two by two comparison (Student-Newman-Keuls test).

\section{Sequence analyses}

The four protein sequences (ACYPI006213-PA, ACYPI 003009-PA, ACYPI004243-PA and ACYPI000044-PA) for the aspartate transaminase enzymatic activity (E.C. 2.6.1.1) were obtained from PhylomeDB [59], together with their corresponding arthropod orthologs and paralogs. The data set was completed with other homologous proteins, extracted from the UniProt database [60], using a stringent e-value $\left(=10^{-6}\right)$ for the BlastP search. Amino acid sequences were then aligned using the software MUSCLE [79] embedded in the phylogeny software SeaView 4.0 [80]. A phylogenetic tree was drawn in order to remove non-homologous proteins and redundant sequences and to reduce the species number in some taxonomic groups of the tree. The alignment was then recalculated and manually corrected. Trees were calculated using Poisson and Kimura distances, with the BIONJ heuristic [81], and by applying maximum likelihood estimations. The tree was rooted, by default, using the longest branch. The mitochondrial target analysis was performed using MITOPROT, an analysis tool for the prediction of mitochondrial targeting sequences ([82]; http://ihg.gsf.de/ihg/mitoprot.html).

\section{Additional files}

Additional file 1: Table S1. List of genes differentially expressed in the three comparisons. A summary of all significant genes identified in this study, with their fold change differences, using a one-way between groups ANOVA for the three pair-wise comparisons: A) EE vs. IE, B) IE vs. $L E$, and $C) L E$ vs. $L 1$. D) Venn diagrams of gene lists of the two contrasts: panel $(I)=$ list A vs. list $B$, panel $(I I)=$ list B vs. list C. E) List of genes with shared probes with other genes.

Additional file 2: Table S2, S8, S9, S10, S12. Table S2. Microarray data validation by qRT-PCR. Table $\mathbf{S} 8$. Relative free amino acid contents during pea aphid development. Table S9. PRIAM analysis results summary. Table S10. MITOPROT analysis results summary. Table S12. Oligonucleotide primers used for qRT-PCR.

Additional file 3: Table S3. List of developmental genes differentially expressed in the three comparisons. A summary of all developmental genes showing significant differential expression for the three pair-wise comparisons A) EE vs. IE, B) IE vs. LE and C) LE vs. L1. D) Developmental genes showing significant expression changes and belonging to specific functional classes (homeobox-containing genes and major components 
of signalling pathways): in red, increasing expression during development and, in blue, decreasing expression during development.

Additional file 4: Table S4. List of functional classes enriched in significant variant genes for the three comparisons. Result of GOSSIP ([73]; http://gossip.gene-groups.net) analysis performed using Blast2GO ([72]; http:// www.blast2go.com/ on the gene showing significant differential expression for the three pair-wise comparisons A) EE vs. IE, B) IE vs. LE and C) LE vs. L1.

Additional file 5: Table S5. List of significant variant genes involved in metabolism from AcypiCyc. Result of the metabolism analysis performed in the AcypiCyc database ([56]; http://acypicyc.cycadsys.org/) on the list of significant variant genes for the three pair-wise comparisons A) EE vs. (E, B) IE vs. LE and C) LE vs. L1.

Additional file 6: Table S6. List of significant variant genes involved in the biosynthesis or the degradation of amino acids. Summary table of annotated amino acids metabolism genes (modified from [29]) showing differential gene expression in the three pair-wise comparisons EE vs. IE, IE vs. LE and LE vs. L1.

Additional file 7: Table S7. List of amino acid transporter genes and their gene expression data. A) Expressions of amino acid transporter genes (as annotated by Price et al. [57]) with, in bold, the genes showing a significant gene expression change during development. Data are presented as log2 intensities for each replicate. B) Summary table of transporter genes showing differential gene expression in the three pairwise comparisons EE vs. IE, IE vs. LE and LE vs. L1.

Additional file 8: Figure S1. EC 2.6.1.1 enzymatic activity proteins alignment. Alignment of the 4 proteins having the aspartate transaminase enzymatic activity (EC 2.6.1.1) in the pea aphid, as performed using ClustalW method in MUSCLE [79], available online at the European Bioinformatics Institute (http://www.ebi.ac.uk/Tools/msa/muscle/).

Additional file 9: Figure S2. Phylogenetic analysis of genes coding for the proteins with EC 2.6.1.1 enzymatic activity. Red circles represent duplication events and brown rectangles represent the corresponding paralogous families, named using consensual annotation. Accession numbers are those from the PhylomeDB (http://phylomedb.org/) or UniProtKB/SwissProt (http://www.uniprot.org/), followed by species names (A. pisum paralogs are written in red). Bootstrap values over $50 \%$ are given at each node of the tree (1000 replicates). The tree (Poisson distance, BIONJ heuristic) was rooted by its longest branch (i.e., the bacterial branch). Scale 0.1 amino acid substitutions by position (257 informative sites). Although the three clades, named AATC2, AATC1 and AATC, are well supported by bootstrap values and always conserved, their respective positioning is not clear, varying according to the tree-building methods used, as illustrated by the very short branches separating them. The number of coding exons for each gene (when available) is given in square brackets after the AATM protein names.

Additional file 10: Table S11. Cuticle precursor and cuticular protein genes. Expression levels of the mRNA (log2 intensities for each replicate) and fold-change differences (in log2) for mRNA showing differential expression in the three pair-wise comparisons EE vs. IE, IE vs. LE and LE vs. L1: in red, increasing expression during development and, in blue, decreasing expression during development. A) Genes coding for the enzymes involved in the synthesis of DOPA and dopamine starting from tyrosine. B) Genes coding for cuticular proteins.

\section{Abbreviations}

EC: Enzyme commission (a numerical classification scheme for enzymes, based on the chemical reactions they catalyse); PCR: Polymerase chain reaction; HPLC: High-performance liquid chromatography

\section{Competing interests}

The authors declare that they have no competing interests.

\section{Authors' contributions}

The authors have made the following declarations concerning their contributions. AR, GF, HC, FC and SC conceived and designed the experiments. AR, KG, GD, NB and MR performed the experiments. AR, GF, PBP, HC, FC and SC analysed the data. PBP, PS and YR contributed reagents/ materials/analysis tools. AR, GF, PBP, HC, FC and SC contributed to text, tables and figures in the paper. AR, FC and SC wrote the paper. All authors read and approved the final manuscript.

\section{Acknowledgements}

Funding: This work was supported by the Agence National de la Recherche (ANR, France), the Biotechnology and Biological Sciences Research Council (BBSRC, UK) « MetNet4SysBio » project grant (2008-2010), and an INSA-Lyon BQR program grant (2008-2009) to SC. AR was the recipient of a PhD fellowship from the French Ministry of Research (2008-2011). The authors would like to thank Pierre Masselot, who worked on the data during his statistics training internship and contributed useful feedback. The authors are grateful to Alain Clavel for plant production and to Valerie James for the English language editing of the final manuscript.

\section{Author details}

'Insa-Lyon, UMR203 BF2I, Biologie Fonctionnelle Insectes et Interactions, Villeurbanne F-69621, France. Inra, UMR203 BF2I, Biologie Fonctionnelle Insectes et Interactions, Villeurbanne F-69621, France. ${ }^{3}$ Université de Lyon, Lyon F-69000, France. ${ }^{4}$ Inria Rhône-Alpes, Bamboo, Monbonnot Saint-Martin F-38330, France.

Received: 19 September 2012 Accepted: 14 March 2013

Published: 10 April 2013

\section{References}

1. Buchner P: Symbiosis in animals which suck plant juices. In Endosymbiosis of Animals with Plant Microorganisms. Edited by Buchner P. New York: Interscience; 1965:210-432.

2. Douglas AE: The microbial dimension in insect nutritional ecology. Funct Ecol 2009, 23:38-47.

3. Baumann P, Moran NA, Baumann L, Dworkin M: Bacteriocyte-associated endosymbionts of insects. In The Prokaryotes. Edited by Dworkin M. New York: Springer; 2000:1-55.

4. Baumann P: Biology of bacteriocyte-associated endosymbionts of plant sap-sucking Insects. Annu Rev Microbiol 2005, 59:155-189.

5. Ziegler H, Zimmermann DL, Milburn JA: Nature of Substances in Phloem: Nature of Transported Substances. In Transport in Plants I - Phloem Transport, Volume 1. Edited by Zimmermann DL, Milburn JA. Berlin: Springer-Verlag; 1975:59-100.

6. Liadouze I, Febvay G, Guillaud J, Bonnot G: Metabolic fate of energetic amino acids in the aposymbiotic pea aphid Acyrthosiphon pisum (Harris) (Homoptera: Aphididae). Symbiosis 1996, 21:115-127.

7. Douglas AE: Nutritional interactions in insect-microbial symbioses: aphids and their symbiotic bacteria Buchnera. Annu Rev Entomol 1998, 43:17-37.

8. Febvay G, Rahbe Y, Rynkiewicz M, Guillaud J, Bonnot G: Fate of dietary sucrose and neosynthesis of amino acids in the pea aphid, Acyrthosiphon pisum, reared on different diets. J Exp Biol 1999, 202:2639-2652.

9. Moran NA, Baumann P: Bacterial endosymbionts in animals. Curr Opin Microbiol 2000, 3:270-275.

10. Shigenobu S, Watanabe H, Hattori M, Sakaki Y, Ishikawa H: Genome sequence of the endocellular bacterial symbiont of aphids Buchnera sp. APS. Nature 2000, 407:81-86.

11. Le Trionnaire G, Hardie J, Jaubert-Possamai S, Simon J-C, Tagu D: Shifting from clonal to sexual reproduction in aphids: physiological and developmental aspects. Biol Cell 2008, 100:441-451.

12. Dixon AFG, Kundu R: Resource tracking in aphids: programmed reproductive strategies anticipate seasonal trends in habitat quality. Oecologia 1998, 114:73-78.

13. Miura T, Braendle C, Shingleton A, Sisk G, Kambhampati S, Stern DL: A comparison of parthenogenetic and sexual embryogenesis of the pea aphid Acyrthosiphon pisum (Hemiptera: Aphidoidea). J Exp Zool B Mol Dev Evol 2003, 295:59-81.

14. Koga R, Meng XY, Tsuchida T, Fukatsu T: Cellular mechanism for selective vertical transmission of an obligate insect symbiont at the bacteriocyte-embryo interface. Proc Natl Acad Sci USA 2012, 109:E1230-1237.

15. Hinde R: The control of the mycetome symbiotes of the aphid Brevicoryne brassicae. Myzus persicae and Macrosiphum rosae. I Insect Physiol 1971, 17:1791

16. Blackman RL, Minks AK, Harrewijn P: Reproduction, cytogenetics and development. In Aphids: Their Biology, Natural Enemies and Control, Volume 2A. Edited by Minks AK, Harrewijn P. Amsterdam: Elsevier; 1987:163-195.

17. Wilkinson TL, Fukatsu T, Ishikawa H: Transmission of symbiotic bacteria Buchnera to parthenogenetic embryos in the aphid Acyrthosiphon pisum (Hemiptera: Aphidoidea). Arthropod Struct \& Development 2003, 32:241-245. 
18. Jayaraj S, Ehrhardt $\mathrm{P}, \mathrm{Schmutterer} \mathrm{H}$ : The effect of certain antibiotics on reproduction of the black bean aphid, Aphis fabae scop. Ann Appl Biol 1967, 59:13-21.

19. Mittler TE: Dietary amino acid requirements of the aphid Myzus persicae affected by antibiotic uptake. J Nutr 1971, 101:1023-1028.

20. Prosser WA, Douglas AE: The aposymbiotic aphid: An analysis of chlortetracycline-treated pea aphid, Acyrthosiphon pisum. J Insect Physiol 1991, 37:713-719.

21. Sasaki T, Hayashi $H$, Ishikawa $H$ : Growth and reproduction of the symbiotic and aposymbiotic pea aphids, Acyrthosiphon pisum maintained on artificial diets. J Insect Physiol 1991, 37:749-756.

22. Douglas AE: Requirement of pea aphids (Acyrthosiphon pisum) for their symbiotic bacteria. Entomol Exp App/ 1992, 65:195-198.

23. Consortium IAG: Genome sequence of the pea aphid Acyrthosiphon pisum. PLoS Biol 2010, 8(2):e1000313.

24. Tamas I, Klasson L, Canbäck B, Näslund AK, Eriksson A-S, Wernegreen JJ, Sandström JP, Moran NA, Andersson SGE: 50 million years of genomic stasis in endosymbiotic bacteria. Science 2002, 296:2376-2379.

25. van Ham RCHJ, Kamerbeek J, Palacios C, Rausell C, Abascal F, Bastolla U, Fernández JM, Jiménez L, Postigo M, Silva FJ, Tamames J, Viguera E, Latorre A, Valencia A, Morán F, Moya A: Reductive genome evolution in Buchnera aphidicola. Proc Natl Acad Sci USA 2003, 100:581-586.

26. Pérez-Brocal V, Gil R, Ramos S, Lamelas A, Postigo M, Michelena JM, Silva FJ, Moya A, Latorre A: A small microbial genome: the end of a long symbiotic relationship? Science 2006, 314:312-313.

27. Lamelas A, Gosalbes MJ, Moya A, Latorre A: The genome of Buchnera aphidicola from the aphid Cinara tujafilina provides new clues about the evolutionary history of metabolic losses in bacterial endosymbionts. Appl Environ Microbiol 2011, 13:4464-4454.

28. Moran NA, McLaughlin HJ, Sorek R: The dynamics and time scale of ongoing genomic erosion in symbiotic bacteria. Science 2009, 323:379382.

29. Wilson ACC, Ashton PD, Calevro F, Charles H, Colella S, Febvay G, Jander G, Kushlan PF, Macdonald SJ, Schwartz JF, Thomas GH, Douglas AE: Genomic insight into the amino acid relations of the pea aphid, Acyrthosiphon pisum, with its symbiotic bacterium Buchnera aphidicola. Insect Mol Biol 2010, 19:249-258.

30. Shigenobu S, Wilson ACC: Genomic revelations of a mutualism: the pea aphid and its obligate bacterial symbiont. Cell Mol Life Sci 2011, 68:1297-1309.

31. Hansen AK, Moran NA: Aphid genome expression reveals host-symbiont cooperation in the production of amino acids. Proc Natl Acad Sci USA 2011, 108:2849-2854

32. Tagu D, Dugravot S, Outreman Y, Rispe C, Simon J-C, Colella S: The anatomy of an aphid genome: from sequence to biology. C R Biol 2010, 333:464-473.

33. Gerardo NM, Wilson ACC: The power of paired genomes. Mol ECol 2011, 20:2038-2040.

34. Gil R, Sabater-Munoz B, Latorre A, Silva FJ, Moya A: Extreme genome reduction in Buchnera spp.: toward the minimal genome needed for symbiotic life. Proc Natl Acad Sci USA 2002, 99:4454-4458.

35. Brinza L, Viñuelas J, Cottret L, Calevro F, Rahbé Y, Febvay G, Duport G, Colella S, Rabatel A, Gautier C, Fayard J-M, Sagot M-F, Charles H: Systemic analysis of the symbiotic function of Buchnera aphidicola, the primary endosymbiont of the pea aphid Acyrthosiphon pisum. C R Biol 2009, 332:1034-1049.

36. Moran NA, Dunbar HE, Wilcox JL: Regulation of transcription in a reduced bacterial genome: nutrient-provisioning genes of the obligate symbiont Buchnera aphidicola. J Bacteriol 2005, 187:4229-4237.

37. Reymond N, Calevro F, Viñuelas J, Morin N, Rahbé Y, Febvay G, Laugier C, Douglas A, Fayard J-M, Charles H: Different levels of transcriptional regulation due to trophic constraints in the reduced genome of Buchnera aphidicola APS. Appl Environ Microbiol 2006, 72:7760-7766.

38. Wilson ACC, Dunbar HE, Davis GK, Hunter WB, Stern DL, Moran NA: A dual-genome microarray for the pea aphid, Acyrthosiphon pisum, and its obligate bacterial symbiont. Buchnera aphidicola. BMC Genomics 2006, 7:50.

39. Viñuelas J, Calevro F, Remond D, Bernillon J, Rahbé Y, Febvay G, Fayard J-M, Charles $\mathrm{H}$ : Conservation of the links between gene transcription and chromosomal organization in the highly reduced genome of Buchnera aphidicola. BMC Genomics 2007, 8:143.

40. Viñuelas J, Febvay G, Duport G, Colella S, Fayard J-M, Charles H, Rahbé Y Calevro F: Multimodal dynamic response of the Buchnera aphidicola pLeu plasmid to variations in leucine demand of its host, the pea aphid Acyrthosiphon pisum. Mol Microbiol 2011, 81:1271-1285.

41. Nakabachi A, Shigenobu S, Sakazume N, Shiraki T, Hayashizaki Y, Carninci P Ishikawa H, Kudo T, Fukatsu T: Transcriptome analysis of the aphid bacteriocyte, the symbiotic host cell that harbors an endocellular mutualistic bacterium, Buchnera. Proc Natl Acad Sci USA 2005, 102:54775482.

42. Brisson JA, Davis GK, Stern DL: Common genome-wide patterns of transcript accumulation underlying the wing polyphenism and polymorphism in the pea aphid (Acyrthosiphon pisum). Evol Dev 2007, 9:338-346.

43. Le Trionnaire $G$, Jaubert S, Sabater-Muñoz B, Benedetto A, Bonhomme J, Prunier-Leterme N, Martinez-Torres D, Simon J-C, Tagu D: Seasonal photoperiodism regulates the expression of cuticular and signalling protein genes in the pea aphid. Insect Biochem Mol Biol 2007, 37:1094-1102.

44. Le Trionnaire G, Francis F, Jaubert-Possamai S, Bonhomme J, De Pauw E, Gauthier J, Haubruge E, Legeai F, Prunier-Leterme N, Simon J, Tanguy S, Tagu D: Transcriptomic and proteomic analyses of seasonal photoperiodism in the pea aphid. BMC Genomics 2009, 10:456

45. Brault V, Tanguy S, Reinbold C, Le Trionnaire G, Arneodo J, Jaubert-Possamai S, Guernec G, Tagu D: Transcriptomic analysis of intestinal genes following acquisition of pea enation mosaic virus by the pea aphid Acyrthosiphon pisum. J Gen Virol 2010, 91:802-808.

46. Hunt BG, Brisson JA, Yi SV, Goodisman MAD: Functional conservation of DNA methylation in the pea aphid and the honeybee. Genome Biol Evol 2010, 2:719-728

47. Gallot A, Shigenobu S, Hashiyama T, Jaubert-Possamai S, Tagu D: Sexual and asexual oogenesis require the expression of unique and shared sets of genes in the insect Acyrthosiphon pisum. BMC Genomics 2012, 13:76.

48. Bermingham J, Wilkinson T: Embryo nutrition in parthenogenetic viviparous aphids. Physiological Entomol 2009, 34:103-109.

49. Douglas A: Reproductive failure and the free amino acid pools in pea aphids (Acyrthosiphon pisum) lacking symbiotic bacteria. J Insect Physiol 1996, 42:247-255

50. Wilkinson $\mathrm{T}$, Ishikawa $\mathrm{H}$ : The assimilation and allocation of nutrients by symbiotic and aposymbiotic pea aphids, Acyrthosiphon pisum. Entomol Exp App/ 1999, 91:195-201.

51. Wilkinson $\mathrm{T}$, Ishikawa $\mathrm{H}$ : Injection of essential amino acids substitutes for bacterial supply in aposymbiotic pea aphids (Acyrthosiphon pisum). Entomol Exp Appl 2000, 94:85-91.

52. Bermingham J, Wilkinson TL: The role of intracellular symbiotic bacteria in the amino acid nutrition of embryos from the black bean aphid. Aphis fabae. Entomologia Experimentalis et Applicata 2010, 134(3):272-279.

53. Bermingham J, Rabatel A, Calevro F, Vinuelas J, Febvay G, Charles H, Douglas A, Wilkinson T: Impact of host developmental age on the transcriptome of the symbiotic bacterium Buchnera aphidicola in the pea aphid Acyrthosiphon pisum. Appl Environ Microbiol 2009, 22:7294-7297.

54. Pfaffl M, Horgan G, Dempfle L: Relative expression software tool (REST) for group-wise comparison and statistical analysis of relative expression results in real-time PCR. Nucleic Acids Res 2002, 30:e36.

55. Shigenobu S, Bickel RD, Brisson JA, Butts T, Chang C-C, Christiaens O, Davis GK, Duncan EJ, Ferrier DEK, Iga M, Janssen R, Lin G-W, Lu H-L, McGregor AP, Miura T, Smagghe G, Smith JM, van der Zee M, Velarde RA, Wilson MJ, Dearden PK, Stern DL: Comprehensive survey of developmental genes in the pea aphid, Acyrthosiphon pisum: frequent lineage-specific duplications and losses of developmental genes. Insect Mol Biol 2010, 19:47-62.

56. Vellozo AF, Véron AS, Baa-Puyoulet P, Huerta-Cepas J, Cottret L, Febvay G, Calevro F, Rahbé Y, Douglas AE, Gabaldón T, Sagot M-F, Charles H, Colella S: CycADS: an annotation database system to ease the development and update of BioCyc. Database 2011:bar008.

57. Price DRG, Duncan RP, Shigenobu S, Wilson ACC: Genome expansion and differential expression of amino acid transporters at the aphid/Buchnera symbiotic interface. Molecular biology and evolution 2011.

58. Claudel-Renard C, Chevalet C, Faraut T, Kahn D: Enzyme-specific profiles for genome annotation: PRIAM. Nucleic Acids Res 2003, 31:6633-6639.

59. Huerta-Cepas J, Capella-Gutierrez S, Pryszcz LP, Denisov I, Kormes D, Marcet-Houben M, Gabaldón T: PhylomeDB v3.0: an expanding repository of genome-wide collections of trees, alignments and phylogeny-based orthology and paralogy predictions. Nucleic Acids Res 2010, 36:D491-496. 
60. Bairoch A, Apweiler R, Wu CH, Barker WC, Boeckmann B, Ferro S, Gasteiger E, Huang H, Lopez R, Magrane M, et al: The Universal Protein Resource (UniProt). Nucleic Acids Res 2005, 33:D154-159.

61. Colombani J, Raisin S, Pantalacci S, Radimerski T, Montagne J, Léopold P: A nutrient sensor mechanism controls Drosophila growth. Cell 2003, 114:739-749.

62. Attardo GM, Hansen IA, Shiao S-H, Raikhel AS: Identification of two cationic amino acid transporters required for nutritional signaling during mosquito reproduction. J Exp Biol 2006, 209:3071-3078.

63. Duncan RP, Nathanson L, Wilson AC: Novel male-biased expression in paralogs of the aphid slimfast nutrient amino acid transporter expansion. BMC Evol Biol 2011, 11:253.

64. Bernays EA, Klein BA: Quantifying the symbiont contribution to essential amino acids in aphids: the importance of tryptophan for Uroleucon ambrosiae. Physiol Entomol 2002, 27:275-284.

65. Hiruma K, Riddiford LM: The molecular mechanisms of cuticular melanization: the ecdysone cascade leading to dopa decarboxylase expression in Manduca sexta. Insect Biochem Mol Biol 2009, 39:245-253.

66. Andersen SO: Insect cuticular sclerotization: a review. Insect Biochem Mol Biol 2010, 40:166-178.

67. Schneider J, Buness A, Huber W, Volz J, Kioschis P, Hafner M, Poustka A, Sultmann $H$ : Systematic analysis of T7 RNA polymerase based in vitro linear RNA amplification for use in microarray experiments. BMC Genomics 2004, 5:29.

68. Irizarry RA, Hobbs B, Collin F, Beazer-Barclay YD, Antonellis KJ, Scherf U, Speed TP: Exploration, normalization, and summaries of high density oligonucleotide array probe level data. Biostatistics 2003, 4:249-264.

69. Smyth G: Linear models and empirical bayes methods for assessing differential expression in microarray experiments. Stat Appl Genet Mol Biol 2004, 3:Article3.

70. Dudoit S, Shaffer J, Boldrick C: Multiple hypothesis testing in microarray experiments. Stat Sci 2003, 18:71-103.

71. Saeed A, Sharov V, White J, Li J, Liang W, Bhagabati N, Braisted J, Klapa M, Currier T, Thiagarajan M, Sturn A, Snuffin M, Rezantsev A, Popov D, Ryltsov A, Kostukovich E, Borisovsky I, Liu Z, Vinsavich A, Trush V, Quackenbush J: TM4: a free, open-source system for microarray data management and analysis. Biotechniques 2003, 34:374-378.

72. Conesa A, Götz S, García-Gómez JM, Terol J, Talón M, Robles M: Blast2GO: a universal tool for annotation, visualization and analysis in functional genomics research. Bioinformatics 2005, 21:3674-3676.

73. Blüthgen N, Brand K, Cajavec B, Swat M, Herzel H, Beule D: Biological profiling of gene groups utilizing Gene Ontology. Genome Inform 2005, 16:106-115

74. Rychlik W: OLIGO 7 primer analysis software. Methods Mol Biol 2007, 402:35-60.

75. Brisson JA, Ishikawa A, Miura T: Wing development genes of the pea aphid and differential gene expression between winged and unwinged morphs. Insect Mol Biol 2010, 19:63-73.

76. Pfaffl M, Tichopad A, Prgomet C, Neuvians T: Determination of stable housekeeping genes, differentially regulated target genes and sample integrity: BestKeeper-Excel-based tool using pair-wise correlations. Biotechnol Lett 2004, 26:509-515.

77. Pfaffl M: A new mathematical model for relative quantification in real-time RT-PCR. Nucleic Acids Res 2001, 29:e45.

78. Henderson J, Ricker R, Bidlingmeyer B, Woodward C: Rapid, accurate, sensitive, and reproducible HPLC analysis of aminoacids. Amino acid analysis using Zorbax Eclipse-AAA columns and the Agilent 1100 HPLC. Agilent Technologies Inc, Publication Number 5980-1193E 2000:1-10. http:// www.chem.agilent.com/Library/chromatograms/59801193.pdf.

79. Edgar RC: MUSCLE: multiple sequence alignment with high accuracy and high throughput. Nucleic Acids Res 2004, 32:1792-1797.
80. Gouy M, Guindon S, Gascuel O: SeaView version 4: A multiplatform graphical user interface for sequence alignment and phylogenetic tree building. Mol Biol Evol 2010, 27:221-224.

81. Gascuel O: BIONJ: an improved version of the $\mathrm{NJ}$ algorithm based on a simple model of sequence data. Mol Biol Evol 1997, 14:685-695.

82. Claros MG, Vincens P: Computational method to predict mitochondrially imported proteins and their targeting sequences. Eur J Biochem 1996, 241:779-786.

doi:10.1186/1471-2164-14-235

Cite this article as: Rabatel et al:: Tyrosine pathway regulation is host-mediated in the pea aphid symbiosis during late embryonic and early larval development. BMC Genomics 2013 14:235.

\section{Submit your next manuscript to BioMed Central and take full advantage of:}

- Convenient online submission

- Thorough peer review

- No space constraints or color figure charges

- Immediate publication on acceptance

- Inclusion in PubMed, CAS, Scopus and Google Scholar

- Research which is freely available for redistribution

Submit your manuscript at www.biomedcentral.com/submit
C) Biomed Central 